Alicante Journal of English Studies 27(2014): 107-124

\title{
The Medical Recipes in the Antidotary in GUL MS Hunter 513 (ff. 37v-96v)
}

\author{
Teresa Marqués-Aguado \\ University of Murcia \\ tmarques@um.es
}

\begin{abstract}
Many Middle English medical texts contain medical recipes where remedies for various conditions are put forward. Recent scholarly research has characterised the recipe text-type from a linguistic viewpoint and also according to its elements, paying special attention to the writing tradition that the texts they are found in belong to. In this line, the present article explores and characterises the recipes contained in a $15^{\text {th }}$-century Antidotary found in GUL MS Hunter 513 (ff. 37v-96v) according to the two parameters mentioned. This analysis is based on the previous evaluation of the writing tradition where the text should be placed according to its composition.
\end{abstract}

Keywords: recipe, text-type, writing tradition, Middle English, antidotary, manuscript studies.

\section{Introduction}

The recipe as a text-type in the English vernacular can be traced back to as early as the $10^{\text {th }}$ century (Carroll 2004: 175), ${ }^{2}$ although the term recipe as such to designate this text-type is not recorded until the late $14^{\text {th }}$ century (Carroll, 1999: 28; Carroll, 2004: 190). ${ }^{3}$ This does not imply that the features of recipes had to necessarily change over time; rather to the contrary, they have preserved their main features remarkably well (Görlach 1992: 756). 
Recipes have a clear writing purpose (Taavitsainen, 2001: 86; Carroll, 2004: 187), which is that of providing instructions on how to prepare some kind of medicine, meal or utility, as Taavitsainen explains (2001: 86). Different types of recipes may be found (medical, culinary, etc.), but the instructive function prevails in all cases (QuintanaToledo, 2009: 24). ${ }^{4}$ This is a rather broad definition of what recipes - regardless of their end purpose - are, but this article will exclusively focus on medical ones (particularly those in a scientific Middle English text, described in section 2), which were all generally aimed at providing tools or procedures to help restore a patient's condition or the balance of humours. ${ }^{5}$

Medical recipes are frequently encountered in medical and scientific texts throughout the medieval period. Yet, it has been claimed that not all recipes display the same features in all varieties of texts. They have been typically considered to form the basis of so-called remedybooks rather than of surgical or special medical treatises, although the last two could also contain embedded recipes - that is, those that appear integrated within longer texts (Taavitsainen, 2001: 86, 95). The differences between remedybooks and learned texts actually go beyond those regarding recipes, since they represent altogether different writing traditions. Taavitsainen, Pahta and Mäkinen, who work on the basis of the traditional division by Voigts (1986: 322), divide texts into those representing the learned tradition of writing (i.e. surgical and specialised texts), and remedies and materia medica (2006: 86). The learned tradition only developed in English during the late $14^{\text {th }}$ century (Taavitsainen and Pahta, 1998: 159), whereas remedybooks had been in use since the $10^{\text {th }}$ or $11^{\text {th }}$ centuries (Voigts, 1986: 322-323). Besides, learned texts were for the most part translations of works originated in the Continent or that had been adapted from Latin sources (Pahta and Taavitsainen, 2004: 14). Each of these traditions was likely to be addressed to a particular specialised audience (i.e. learned treatises for surgeons and physicians, and remedybooks for relatively lay people), although research on the issue of readership still lies ahead (Taavitsainen, 1994: 330).

Recipes in remedybooks and learned writings vary in other two ways. On the one hand, the recipes in remedybooks have been described as relatively standardised as to their format, whereas those in learned texts tend to display a higher degree of variation (Taavitsainen, 2006: 692). These differences might relate in turn to the function of each tradition: remedybooks served as handbooks for quick reference, while learned treatises illustrated healing practices (Taavitsainen, 2006: 692). On the other, Carroll (2004: 184) has pointed out that whereas the recipes in remedybooks may be read individually (and, eventually, the order in which they are read is of little importance), those in learned texts display an organisational principle that must be borne in mind. This revolves again around the idea that remedybooks were normally used as quick reference books, as opposed to the learned tradition, which provided extensive theoretical descriptions in which recipes were embedded, hence the need for a more fixed order.

Different as the two traditions may seem, such a clear-cut division was not always that neat, especially at the end of the Middle English period. It has been widely reported that the two traditions sometimes overlapped, and this may explain, for example, that 
remedybooks occasionally contained learned materials (Taavitsainen, 2006: 659). An example of this overlap is the text under study, which will be examined to assess the extent to which the recipes it presents accommodate to the variety of text it is assumed to belong to. For the purpose, its recipes will be analysed from two standpoints: linguistic elements and recipe elements.

\section{Description of the treatise}

The treatise under analysis is a Middle English Antidotary held in Glasgow, University Library, MS Hunter 513 (ff. 37v-96v) - hereafter H513 - , a $15^{\text {th }}$-century manuscript. ${ }^{6}$ It is peculiar in its composition, as discussed further down, which turns it into an interesting text in which the format and features of recipes may be assessed in the light of the variety of text. Catalogued as an anonymous text (Young and Aitken 1908: 421; Cross 2004: 35), its title seems to indicate that it belongs to the remedybook tradition. Yet, it is only recently that it has been identified as a text that brings together parts of two works by two extremely reputed medieval French surgeons, Henri de Mondeville and Guy de Chauliac (Marqués-Aguado, 2008: 58-64). Compilations of texts from various sources were not uncommon in the medieval period, a practice that "is especially true for medieval English medical writings, since compilation and translation from other sources were the principal methods of textual production" (Getz 1998: 36). ${ }^{7}$ This attribution would then lead to the re-location of H513 under the learned tradition of writing.

The text blends part of the fifth chapter of Mondeville's surgical text (ff. 37v-88v in H513; hereafter, the "Mondeville section"), which was conceived as an antidotary itself, ${ }^{8}$ and part of the second doctrine of the seventh (and last) book of Guy de Chauliac's Magna Chirurgia (ff. 88v-96v; henceforth, the "Chauliac section"). Both parts can be then safely ascribed to the group of surgical texts. The "Mondeville section" discusses the seven operations of medicines (that is, repellents or repercussives, resolutives or resolvents, maturatives or suppuratives, mundificatives or cleansing medicines, incarnatives, corrosives and ruptories [or caustic medicines], and finally remollitives or emollients) from a rather theoretical viewpoint, whereas the "Chauliac section" provides a series of remedies for several ailments arranged a capite ad pedem, that is, from head to foot - the typical organisation deriving from Greek times. This implies that, notwithstanding their similarities as learned texts, the two sections pursue different aims and follow different organisational principles.

It must be stressed that an additional source for certain recipes in H513 has been identified through reading and later comparison to another copy of the text, as found in Nicaise's modern translation into French (1893). This comparison has evinced that the "Mondeville section" in H513 contains certain recipes (see Table 1 below) that are not attested in the copy in French. Additional evidence deriving from the occasional disruption of coherence in the description and/or enumeration of recipes supports the existence of a distinct (and unidentified) source for such recipes. An example will suffice at this point: the added recipes in f. $45 \mathrm{v}$ introduce three plasters which come 
immediately after a list of five types of ointments, but the link between both sets is not evident or even explained, nor is the link between the recipes themselves. The reader is also left to assume that these served the same purpose, since this is not explicitly mentioned in some recipes. On other occasions, as in ff. $72 \mathrm{v}-73 \mathrm{r}$, the number of recipes is coherently presented in the Middle English text, although this may entail the addition of one recipe compared to the French copy. The insertion of such foreign or interpolated material was not a rare practice in medieval times, when it was possible to add material from elsewhere to a copy being made, or to conflate texts (as with H513). In the text under scrutiny no overt device marks these recipes as foreign material and no source is ever mentioned, although some of them are also found in the Leechbook edited by Dawson (1934). This conflation of material is especially interesting for an analysis of the recipes in $\mathrm{H} 513$ from the point of view of writing traditions.

Interestingly enough, there are also recipes in the "Chauliac section" that appear not only in this surgical text, but also in the Leechbook mentioned above (Dawson, 1934). However, and contrary to what we find in the "Mondeville section", this material has not been inserted into Chauliac's text from elsewhere, but rather extraposed from it and re-used in another text from a different writing tradition. As a matter of fact, the recipes that have been transferred to the Leechbook (e.g. one for the eyes by Master Peter of Spain, or one for head problems by Master Anselme of Janua, reproduced in (29) below) are also preserved in Nicaise's French translation of Chauliac's text (1890), as well as in Ogden's edition in Middle English (1971). This is especially noteworthy, as it implies that borrowing of material worked both ways. ${ }^{9}$

In order to analyse the differences between the recipes in the two sections and in the interpolated material, a linguistic analysis of the recipes, along with a study of their elements, will be particularly helpful with a view to assessing they way in which this "transmission into another tradition" (Taavitsainen, 2001: 94) was carried out in H513. In doing so, the peculiarities and specificities of the text surveyed will be brought to light.

\section{Analysis of the recipes in $\mathbf{H 5 1 3}$}

The medical recipes in $\mathrm{H} 513$ have been manually extracted from the corresponding transcription of the text. ${ }^{10}$ The recipes, which amount to 193, are distributed into the "Mondeville section" and the "Chauliac section" as shown in Table 1 (first column), where the number of recipes per chapter in each section is provided. The interpolated material is counted for the "Mondeville section" - there being no interpolated material into the "Chauliac section": 


\begin{tabular}{|c|c|c|c|c|}
\hline SECTION & CHAPTER & $\begin{array}{c}\text { NUMBER OF } \\
\text { RECIPES }\end{array}$ & $\begin{array}{c}\text { NUMBER OF } \\
\text { INTERPOLATIONS }\end{array}$ & TOTALS \\
\hline \multirow{8}{*}{$\begin{array}{l}\text { "Mondeville } \\
\text { section" }\end{array}$} & Chapter 1 & 13 & 2 & 15 \\
\hline & Chapter 2 & 19 & 3 & 22 \\
\hline & Chapter 3 & 18 & 0 & 18 \\
\hline & Chapter 4 & 22 & 0 & 22 \\
\hline & Chapter 5 & 31 & 1 & 32 \\
\hline & Chapter 6 & 34 & 4 & 38 \\
\hline & Chapter 7 & 7 & 1 & 8 \\
\hline & TOTAL & 144 & 11 & 155 \\
\hline \multirow{9}{*}{ "Chauliac section" } & Chapter 1 & 8 & 0 & 8 \\
\hline & Chapter 2 & 17 & 0 & 17 \\
\hline & Chapter 3 & 2 & 0 & 2 \\
\hline & Chapter 4 & 2 & 0 & 2 \\
\hline & Chapter 5 & 2 & 0 & 2 \\
\hline & Chapter 6 & 8 & 0 & 8 \\
\hline & Chapter 7 & 8 & 0 & 8 \\
\hline & Chapter 8 & 2 & 0 & 2 \\
\hline & TOTAL & 49 & $\mathbf{0}$ & 49 \\
\hline
\end{tabular}

Table 1. Distribution of recipes into sections and chapters

Although the "Chauliac section" is shorter (c. 9 folios) than the "Mondeville section" (c. 50 folios), the proportion of recipes it contains is clearly higher. This may be explained by the fact that the "Chauliac section" focuses on remedies rather than on theoretical discussions, as explained in section 2. The second chapter in the "Chauliac section" stands out, as it gathers more than $30 \%$ of the total number of recipes in the section. The figures also reveal that the interpolations are not evenly distributed across the chapters in the "Mondeville section", although there are not salient differences either.

The analysis of the recipes in H513 presented below is twofold and focuses on linguistic features and recipe elements. ${ }^{11}$ This brings together earlier work on the identification of recipe elements such as composition, application, procedure, etc. (see Stannard 1982 or Hunt 1990), and more recent research on the linguistic elements of recipes (e.g. Görlach, 1992, Carroll, 1999 or Taavitsainen, 2001).

\subsection{Analysis of linguistic features}

Carroll's and Taavitsainen's proposals have been used as complementary sources of information for this analysis, and the following features have been explored: form of the title or heading, 'telegrammatic' style, verb forms, personal and possessive pronouns, object deletion, temporal structuring and parataxis. 


\subsubsection{Form of the title or heading}

Scholars report that recipes in remedybooks are often introduced by a noun phrase plus postmodification, or else by a phrase starting with 'for'. In turn, in learned treatises the purpose of the remedy must be normally inferred from the context and there are indexing devices other than 'for', such as 'another', 'also', etc. (Taavitsainen, 2001: 99; Carroll 2004: 181).

As explained above, most of the recipes in the "Mondeville section" are integrated within the theoretical background that discusses the properties and some general remarks of each of the seven operations of medicines, hence the shift from expository to instructive fragments, and vice versa. In each chapter, various groups of remedies (oils, ointments, powders, etc.) are provided. Chapter two may serve as a good example: it includes six oils, five ointments, three plasters and four cataplasms, plus three interpolated recipes that follow the ointments, as mentioned in section 2 . The different sets of remedies are introduced by sentences such as "at pis tyme ther bene sixe maner of oyles" (f. 44r) or "Al so ther bene 5 - ruptories I the which bene good to oure purpos" (f. $71 \mathrm{v}$ ), and then the enumeration of the various remedies follows, as shown in (1):

(1) Ther ben $\boldsymbol{e} \cdot \mathbf{4} \cdot$ cataplasmas the whiche ben $\boldsymbol{g} \operatorname{good}$

to owre purpos $\mathbb{I}$ The fyrste take $[\ldots] \|$

II The secounde take $[\ldots]$

II The thyrde $\sim[\ldots]$

The $4 \cdot$ is oure owne cataplasma [...] (ff. 46v-47r)

The interpolated material, however, is introduced by sentences like "A good enplaster for to breeke bones andl for sodeyne goutes for styches and sodeyne bollyngl and vncome ache", "Al nother Take pe Inner rynde" and "A · good Emplaster for hoot enpostumes" (f. 45v); "Al cataplasma take betoyne" (ff. 59r-59v); "A nother precious powder", "A nother pouder" and "A wasshing for the same olde sore" (ff. 69v-70r); or "A nother oynement" (ff. 85v-86r). Some of the recipes, therefore, make use of devices that are normally expected for learned texts, like the use of 'another'.

In the "Chauliac section" the theoretical discussion is substantially curtailed so that the heading plays a much more prominent role. Chapters are preceded by rubricated titles that indicate the set of medicines discussed, following the a capite ad pedem arrangement. These remedies are introduced with very few linking devices, as shown in (2), extracted from chapter 4 . In some cases, 'for' is used to introduce a recipe, a device that scholars link to remedybooks rather than to learned texts:

(2) The 4 chapeter

is of helpyng of the sculderis and the bakke

For akpe of Shuldres medle marciatoun and

agrippa to geder for gibbosite of pe bakke Aui=

cen preiseth the emplaster of Achorus II Take

Achorus Elena campana sauine ana $\mathrm{j}$ quarter bdelli= 


\author{
um dim quart castorum ana ounce. sethe hem with wyne \\ and oyle tylle pat pe wyne and pe oyle be con= \\ sumed and of pe same oyle with wexe make an \\ oynement $\mathbb{I}$ Ciragra manum is cured as ben \\ oper fleumatik enpostumes but a speciall $\mathrm{Em}=$ \\ plaster of Munpellers made of reed cole sopene \\ with the lye of wode asshen and a lytell vi= \\ neger and a litell salte grounden to gedyr / (f. 93r)
}

\title{
3.1.2. 'Telegrammatic' style
}

Sentences are complete, as explained in Carroll (1999: 29), hence avoiding the so-called 'telegrammatic' style. All the examples in this article, whether extracted from the two learned sections or from the interpolated material, show sentence completeness.

\subsubsection{Verb forms}

As with present-day English, medieval recipes make extensive use of the imperative (Carroll, 1999: 30; Carroll, 2004: 180-181). This feature is particularly evident in the first word(s) of the recipes, which are normally verbs related to cooking, as remarked by Taavitsainen (2001: 99-100). In turn, modals such as 'shall' or verbs in the subjunctive are typically avoided.

The imperative prevails in both sections, although 'shall' followed by a verb in the passive voice may be also encountered. Likewise, the subjunctive is quite common when presenting hypothetical situations (with 'if'), as in (3) and (4):

(3) hit

shall be made thus The gommes shall be tempered in vinegre and dissolued with a lente fire and be reme= naunt shall be made as it is saide a forne (f. $71 \mathrm{v})$

(4) And yf pat a man holde pis drynke it is good tokene and yf he brake hit vppe a yene it is yuell token (f. 88v)

The interpolated material shows a high number of imperative forms, too, although in those cases where subordinate clauses are employed (conditional or purpose ones, mainly), the subjunctive is also used, as in (5):

(5) and than do hit yn a panne over the fyre and stere hit well bat it brenne not to the bothume (f. 40r)

\subsubsection{Personal and possessive pronouns}

Carroll shows that possessive pronouns may appear (1999: 30), but again the different varieties of texts show diverging patterns, and remedybooks are more likely to include personal pronouns than academic treatises. The alternative is that of articles, which are 
reported to be more frequent in learned treatises. Taavitsainen, in turn, is more concerned with the use of either passive constructions or more personal ones (2001: 100-101) and, according to her and in line with Carroll's views, personal guidance is more common in remedybooks (with first and second person pronouns), whereas passive or more detached constructions typically feature in surgical tracts.

In this vein, it is interesting to note that the interpolated material in H513 does show second person constructions — an example is found in (6) - although passives also appear, as in (7):

(6) And at yche

tyme pu leyst it one ley a plaster of resolutiue

a bove for it wolle swelle pe flessh (f. 70r)

(7) and stere euermore

well tyll pe iuse be consumed so that ther leve

nothing but as it were the oyle (f. 86r)

In the "Chauliac section" passives and detached constructions presenting either the disease or the remedy as the subject are recurrent, as in (8), although second person pronouns are occasionally found, as in (9). In these cases, active constructions with personal subjects ("summel men" in (9), the name of a scholar, etc.) are also used:

(8) Vlceraciouns of pe yerde

shalbe wasshen with water of allumme (f. 94v)

(9) and pu shalt wonder manẏ men boyle

lyterge by் hym selfe with vineger and summe

men adde per to a litell Ceruse (f. 90v)

As for the "Mondeville section", constructions with the second person pronoun are used not only in the recipes, but also in the theoretical discussion preceding lists of remedies, as in (10). Passages such as (11), which shows a persistent use of personal and possessive second person pronouns, are however comparatively infrequent. These examples oppose the tendency described for learned writing. It must be stressed, though, that second person pronouns are mostly found in subordinate clauses:

(10) and yf

pou wylte make it better stampe fresshe herbes as pu II

doyst a fore $[\ldots]$

and seith it and streyne it as pu dedyst

a fore (ff. 40r-40v) 
(11) medecynes that be compound If ffor yf bu decocte onẏ sympell medecyns pat fallene to pi purpos pu shalt foment pe place with pe water of pyn decoctioun tyll pat hit wex reed and swelle and anone after leẏ to thy medecyns pat be good to thy purpos II And yf so be pat whan pu resolues (f. 47v)

\subsubsection{Object deletion}

According to Carroll and Taavitsainen, object deletion is rare in medical recipes (1999: 31 and 2001: 100, respectively), and this holds true in H513, too, both in the interpolated material (see (12)), and in the two sections, as shown in (13). These examples show, however, that PDE 'to lay' is sometimes found without an object, as opposed to the other verbs:

(12) and seepe hem to the thyknesse

of an Enplaster and ley to the soore all hoote (f. $45 \mathrm{v}$ )

(13) encorpere hem vp on pe fyre and make an emplaster and ley ther to (f. 96v)

Nonetheless, the very nature of recipes, in which instructions are provided and imperatives are therefore frequent, makes objects be hardly ever omitted; otherwise, incomplete messages would have been rendered, possibly producing severe consequences on patients.

\subsubsection{Temporal structuring}

Generally speaking, recipes follow the chronological order to prepare the corresponding remedy, so that the wording reproduces the procedure (see also Taavitsainen 2001: 98). This usually implies the addition of lexical items (especially 'then') to reinforce the sequencing of the various steps, as in (14), taken from the "Mondeville section". This lexical choice goes hand in hand with the preference for imperatives:

(14) tylle

pat pe honye be thykke and pan adde ther

to other honye tylle pat it be fluxible $\sim$ (f. $55 \mathrm{r}$ )

In the "Chauliac section" there are also temporal linking devices, although they are not as common as in the "Mondeville section", coordination being preferred, as shown in (15): 
(15) The $\cdot 2$.

is putte oper sette a gommor for to white and make clene pe visage and Rasis techith hit $\mathrm{II}$

Take floure of Chiches of benes of barlye off almaundes blaunched dragagant ana oone partie pe seed Radych half yn one partie make

pouder per of and distempere it with mylke and

anoynte pe visage per with all be nyght and $\|$

wasshe it in pe mor nyng with water of brenne (ff. 90r-90v)

Interpolations also contain certain lexical items to reinforce the sequencing of steps to be followed, such as the conjunction 'when' followed by 'then', as in (16), or a series or coordinated clauses, sometimes reinforced with 'then', as in (17):

\section{(16) And}

whan pe grece is stamped with the herbes pan lete hem stonde infuse (f. 40r)

(17) and seepe he $m$ in whi= te wyne tylle pey be softe and pan put perto

3. ounce of brynne and seepe hem (f.45v)

These examples show that, in general, and despite the occasional use of 'then', the temporal structuring of the recipes widely relies on coordination using 'and'.

\subsubsection{Parataxis}

As also put forward in the relevant literature (e.g. Carroll, 1999: 31), most of the recipes in the text (particularly the section where the procedure is described) contain long series of short coordinate clauses, the majority of which include cooking verbs such as 'seethe', 'boil', 'take', etc., as already shown in the preceding examples, particularly those in section 3.1.6.

In the case of the interpolations, however, juxtaposition is favoured, as shown in (18):

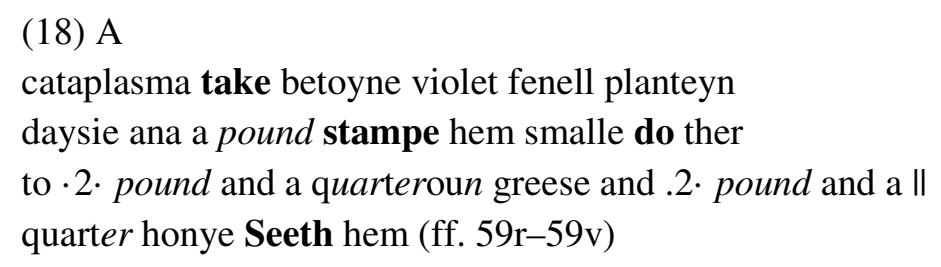

\subsection{Analysis of recipe elements}

According to Stannard, the following types of information (also called Fachinformation) can be found in recipes: purpose; ingredients, equipment and 
procedure; application and administration; rationale; and incidental data (1982: 60-65). Out of these, only the procedure was compulsory (Carroll, 2004: 179). ${ }^{12}$

\subsubsection{Purpose}

The purpose of a remedy may appear either at the beginning or at the end of the recipe (Mäkinen 2006: 88-89).

The interpolated material shows a similar number of initial and end positions for the purpose section, with sentences such as "A good enplaster for to breeke bones andl for sodeyne goutes for styches and sodeyne bollyngl and vncome ache" (f. 45v) or the one in (19), which follows from (18):

(19) Seeth hem all to gedir tyll it be wel

medelyd This wille hele ony soore whan it is clen= sid (f. 59v)

In the "Mondeville section", as explained above, the general purpose of a series of remedies is many a time inferred from the general and theoretical discussion at the beginning of each chapter, as in (20). Whenever there is a specific purpose, this is commonly set at the end of the recipe, as shown in (21). This is particularly evident in the recipe for common diachylon: the purposes it may serve are explained at length in f. 46v, after describing its composition:

(20) And pese maturatiues pat folowene ben good

in grete hoote furious materis and ther be. 5 .

of hem (f. 49v)

(21) The $\cdot 4 \cdot$ take the

fylthe of a man $n$ medelyd with honye / brenne

hem to gedyr and make pouder per of and ley

hit to hit corrodith nobely well and grevith

but lytell (f. 69r)

In the case of the "Chauliac section", which lacks such lengthy expository sections, the purpose is overtly conveyed sometimes through longer sentences (22), and some other times through more concise statements (23):

(22) Firste for torcions of pe wombe is preysed well pat growith a twixe the schepis legges (f. 93v)

(23) Rupture II

hathe $\cdot 3 \cdot$ helpes $\mathbb{I}$ The first is an electuarie· (ff. $94 \mathrm{v}-95 \mathrm{r}$ ) 


\subsubsection{Ingredients, equipment and procedure}

The length of the procedure varies depending on the recipe and, in most cases, there is a passing comment on the specific equipment required, if any. An extremely succinct case can be found in the "Mondeville section", reproduced in (24), in which only the ingredients are listed for each remedy, along with the purpose. No further explanations are given:

(24) Ther bene poudres and oynementis pe which bene made of these sympel medecines a foresaide of the whiche ther bene -4. II The fyrst take smalle frank encense aloes sang dragoun and it regenderyth flessh som dele and encarnyth al solThe $\cdot 2 \cdot$ take smalle frankencense one partie saunk dragoun $\cdot 2 \cdot$ par= ties calce viue $\cdot 3 \cdot$ parties $\mathbb{I I}$ The $\cdot 3^{\text {de }}$. take 2 parties of sarcocolle saunk dragoun balaucia ana one partie olibanum dim one partie hit streyneth blood and per with the flessh $1\left[\right.$ The $\cdot 4^{\text {the }}$. Take saunkdragoun aloes sarcocol mastik coperos ana (f. $59 \mathrm{v}$ )

Yet, the relevant literature reports a difference between the two traditions of writing regarding measurements and quantities, since learned treatises are usually more precise than remedybooks (Taavitsainen, 2001: 103). Nonetheless, the interpolated material in H513 is fairly specific in terms of measures and quantities, as shown in (25), inasmuch as general statements such as 'handful', 'halpennywoth' and so on, are mostly avoided: ${ }^{13}$

(25) A wasshing for the same olde sore

Take $\cdot \mathbf{3}$ ounce of white wyn $\mathbf{j}$ ounce vinegre $\mathbf{j}$ ounce honye

j ounce salte boyle hem well to gedyr a litell

whyle and whanne pe sore hath good flessh

wasshe hit euery day்e tylle hit be hoole (f. 70r)

By the same token, quantities such as 'a virreful', 'a gobeletful' or 'ana' (which indicates the same amount but at times lacks an indication of the specific amount required, as in the last line in (24)) are occasionally used in the two learned sections, although more specific weights are normally provided (ounces, drams, etc.).

\subsubsection{Application and administration}

This element comprises information regarding dosage, frequency and time of application, etc. (Mäkinen, 2006: 91).

Whereas the procedure is fairly long and detailed in the interpolated material, information on application and administration is rarely found, with only one case, i.e. "leyं hit to hoot" (f. 45v).

In the "Mondeville section" there are quite a few indications regarding the application of a remedy (i.e. whether it should be applied hot or cold, whether cotton 
should be employed for the purpose, how many times, etc.), although many recipes still lack detailed information on this matter, as (26) and (27) show:

(26) and ley it

to the place where pou wylte with cotton wet= te yn spetill (f. 69r)

(27) ley hit to twyes on pe dayje (f. 69v)

The "Chauliac section" is similar to the interpolated material in that there are few references to the dosage or the time of application, one of which is shown in (28). Many times, the recipe ends with the last step in the procedure (for instance, 'and make a plaster') and omits any reference to the application, maybe because this knowledge was assumed on the part of the reader:

(28) and giffe pe pacient $\mathbf{a}$ gob=

bet fulle to drinke whanne he goith to bedde (f. $93 \mathrm{v}$ )

\subsubsection{Rationale}

The rationale, that is, the arguments supplied to support the potency of a remedy, is also optional. According to Jones, efficacy phrases are a subtype of tags or phrases which "attest to the value of a given remedy" and in most cases are given in Latin, even if the recipe is entirely rendered in English (1998: 199-200). Her study focuses on the material extracted from a manuscript that seems to conform to the remedybook format and concludes that these elements are frequent. The interpolated material in H513, however, does not contain efficacy phrases.

Statements about the rationale of the recipes in the "Mondeville section" are infrequent, since most recipes come to a sharp end after the procedure is given, as shown in (24). One of the few exceptions is the seventh incarnative powder, which is said to be "pe beste" (f. 61r). This suggests, therefore, that the rationale is probably one of the least important recipe elements in this section.

In turn, the "Chauliac section" shows a certain tendency to present the rationale for remedies featuring short tags such as "and pou shalt wonder" or "for hit is experte and proued", which are nevertheless assumed to be more common in remedybooks (Taavitsainen, 2001: 104).

\subsubsection{Incidental data}

This comprises anecdotes or citations to other scholars. Taavitsainen's claim that the recipes in remedybooks rarely provide detailed references to the source from which they derive, whereas those in learned treatises are fairly exact (2001: 100-102), is not completely fulfilled in H513. In this sense, only 8 of the 49 recipes in the "Chauliac section" contain the name of the scholar who is credited with a particular remedy; anecdotes are also found, as in (29). There are also some vague references, like the one 
in example (9) - "to summel men" - , which are nonetheless more typical of remedybooks:

(29) The $5 \cdot$ fourme is an emplastrum capitale of Mayster Anselme of $\mathbf{I e}=$ ne And it drawith quiture and reyseth vppe bones and encarnyth and helyth And mayster

Peers Bonaunte seyde bat he had preved hit in an houndes hede pat was hurte in to pe breynes and helyd hym (f. 89r)

The proportion is even more reduced in the "Mondeville section", where only two recipes include the name of an acknowledged scholar, as in (30). ${ }^{14}$ Actually, much of the theoretical material in this section suppresses references to the scholars or works that discuss a particular type of medicine or a given remedy, only noticeable when the text is compared to Nicaise's translation into French (1893).

(30) hit helith oolde canke= ry்e soores and be same kankers yef they be newe a malum mortuum and oper suche and henricus de Amonda

Villa seieth he fonde noo better medecyne amonge su= che maner medecines panne pis A duche man

pat was cladde all in skynnes with outene cloope pat brought pis medecyne fyrst to parys And these twoo laste oynementis. a fore saide disceyue be paci= ent for they be not grene (f. 71r)

At the end of the cline we find that none of the interpolated recipes actually mentions any scholar. Therefore, it seems that the "Chauliac section" has preserved this feature of the learned tradition of writing to a greater extent, although with some changes.

\section{Conclusions}

This study has laid bare the peculiar composition of H513, casting light on the various components that contribute to this Antidotary and on the varieties of text that each of them represents. The reasons why they may have come together may be manifold, but they are probably connected with the medieval lack of concern for authorship and the subsequent liking for excision, conflation and blending of texts, paired up, of course, with the utilitarian principle of serving the needs of the user.

Whereas two distinctive sections have been identified as Middle English translations of learned texts, certain material in the form of recipes has been inserted into one of the sections, the "Mondeville section". It must be assumed, however, that these have been placed in the precise points where they serve the purpose of the medicine being discussed, since no clear explanation is given. The facts that this material is also found in a leechbook and that the same leechbook also renders other recipes in the "Chauliac 
section" suggest that this text testifies to the flow of material from one tradition to the other.

As for the elements surveyed, the analysis shows diverging patterns for the three sections, both in terms of linguistic features and of recipe elements. The interpolated material does comply with most expected linguistic features, although some parameters (for instance, the use of 'another' in some titles or headings, the presence of passive and detached constructions, the definiteness and precision of measurements, or the lack of efficacy phrases) diverge from the prototypical recipes of remedybooks. At any rate, it seems safe to identify this interpolated material as having been taken from some other Middle English remedybook, rather than a learned treatise. This hypothesis is supported by the fact that some of these recipes come up in the Leechbook edited by Dawson. Although no systematic comparison with all the other witnesses of the treatise has been carried out, such foreign material is also attested in Glasgow, University Library, MS Hunter 95 and London, British Library, MS Sloane 2463, which implies that the interpolated material came to be considered part of the treatise and of its tradition. The recipes in the sections deriving from the learned texts do not always conform to the prototype of this tradition, and even show differences between them. On the one hand, the "Chauliac section" displays some features that would be expected in remedybooks, such as the use of prepositional phrases with 'for' to introduce a recipe, the sporadic use of second person pronouns, the vagueness of certain measurements or the use of short tags for the rationale, even though its authorship — and, hence, its placement under the learned tradition of writing - cannot be questioned. On the other hand, the "Mondeville section" follows the expected conventions to a greater extent, particularly those concerning linguistic devices. For instance, in this section the organisational principle is especially important, inasmuch as the purpose of many remedies is developed in the preceding theoretical discussion. It occasionally departs from the prototypical recipe in learned texts, as with the use of second person pronouns, the vagueness of some measurements and the lack of incidental data. The text under examination is, therefore, a good example of the exchange of traditions at the level of recipe construction and rendering.

There are further differences between the two learned sections that do not seem to relate however to the peculiarities of the writing tradition they are placed in, but rather respond to purely textual preferences. These concern aspects such as the mechanisms used to foster temporal structuring, the preference for parataxis or juxtaposition, the statement of the purpose of a recipe (as well as the position this occupies in the recipe), or the presence or absence of information on the application of a remedy.

\section{Notes}

1. This research has been carried out with the support of the Spanish Ministry of Science and Innovation (project number FFI2011-26492) and the regional government of the Junta de Andalucía (project number P11-HUM-7597). These grants are hereby gratefully acknowledged. 
An earlier version of this article was presented at the $22^{\text {nd }}$ International SELIM Conference, held at the University of La Rioja in 2010 (September $30^{\text {th }}-$ October $2^{\text {nd }}$ ).

2. A general definition and characterisation of recipes may be found in Görlach (1992: 738739). The term text-type is used throughout to refer to recipes since this article is primarily concerned with the linguistic features that they display, rather than with their function, which would correspond to the term genre (see Carroll 2004: 178, 186 and Quintana-Toledo 2009: 23-24, among others).

3. In fact, the entry for 'recipe' in the Oxford English Dictionary (s.v.) does not provide any quotation dating to before the mid- $16^{\text {th }}$ century.

4. Gorlach's 1992 article focuses on the cookery recipe as a text-type. In turn, Hieatt edits and comments culinary recipes (1996) and Grund accounts for the conventions of alchemical recipes (2003).

5. The theory of humours was first advanced by the Greeks and suggested that the human body was, in a certain way, a microcosm of the universe, so that "[j] ust as the universe was made up of the four basic elements fire (hot and dry), water (cold and wet), earth (cold and dry) and air (hot and wet), so too the body depended for its existence upon four corresponding humours: choler or yellow bile, phlegm or mucus, black bile, and blood" (Rawcliffe, 1995: 31). Good health was the result of the balance of the four humours.

6. Other copies of the same text are held in Glasgow, University Library, MS Hunter 95 (ff. 156r-184r); London, British Library, MSS Sloane 2463 (ff. 153v-193v) and Sloane 3486 (ff. 3-18); New York, Academy of Medicine, MS 13 (ff. 152r-188v); and Oxford, Bodleian Library, MS Ashmole 1468 (ff. 139-171).

7. The same idea is found in Pahta, who states that "many surviving treatises are not original compositions in the modern sense of the word, but conflated texts assembled from various sources" (1998: 16). Taavitsainen, Pahta and Mäkinen highlight that these borrowing practices applied to learned medical writings and remedybooks alike (2006: 84).

8. This term is used to refer to compound medicines (Mäkinen, 2006: 86), which were formed with simple ones (see, for instance, Nicaise 1893: 742). The term antidotary has been usually linked to collections of medical recipes (i.e. remedybooks).

9. A similar situation has been described by Taavitsainen (2001: 94-95) regarding the famous Compendium Medicinae, by Gilbertus Anglicus.

10. This text belongs to the corpus being compiled with this far unedited Middle English scientific texts and which can be consulted at $<$ http://hunter.uma.es $>$. Since the transcription has been employed, the layout and the orthographic and linguistic peculiarities of the text are reproduced in the examples below (colour excepted), with no correction or editorial intervention. Bold indicates the element under discussion in each section, I indicates a line break and II a page break.

11. A similar proposal can be found in Alonso-Almeida (1998-1999).

12. Carroll also discusses recipes in terms of their prototypicality, according to which they "were based upon short, paratactic, imperative clauses" (2004: 179). Additionally, they "prefaced this procedural component with a heading, included specification of ingredients to be used, and ended with an application component" (Carroll, 2004: 189).

13. Quantities were sometimes omitted either because of scribal lack of acquaintance with medical theory or measures, or else because these were taken to be common knowledge (Alonso-Almeida, 1998-1999: 57-58).

14. These names may have been considered superfluous in the process of subsequent copying, or else no need was felt to add them. At any rate, the lack of references does not reveal 
a lack of erudition, but rather testifies to the medieval habit of not acknowledging the sources due to the lack of concern for authority.

\section{References}

Alonso-Almeida, Francisco (1998-1999): “'Gyf hyr pis medycyn': Analysing the MiddleEnglish Recipe Medical discourse”. Revista de Lenguas para Fines Específicos 5-6: 49-81.

Carroll, Ruth (1999): "Middle English recipe as a text-type". Neuphilologische Mitteilungen 100(1): 27-42.

Carroll, Ruth (2004): "Middle English recipes: Vernacularisation of a text-type". In I. Taavitsainen and P. Pahta, eds., Medical and Scientific Writing in Late Medieval England. Cambridge: Cambridge University Press, 174-196.

Cross, Rowin A. (2004): A Handlist of Manuscripts containing English in the Hunterian Collection Glasgow University Library. Glasgow: Glasgow University Library.

Dawson, Warren R. (ed.) (1934): A Leechbook, or Collection of Medical Recipes of the Fifteenth Century, ms no.136 of the Medical Society of London. London: MacMillan and Co.

Getz, Faye Marie (1998): Medicine in the English Middle Ages. Princeton (NJ): Princeton University Press.

Görlach, Manfred (1992): "Text-types and Language History: The Cookery Recipe". In J. Svartvik and H. Wekker, eds., History of Englishes. New Methods and Interpretations in Historical Linguistics. Berlin, New York: Mouton de Gruyter, 736-761.

Grund, Peter (2003): "The Golden Formulas: Genre Conventions of Alchemical Recipes in the Middle English Period". Neuphilologische Mitteilungen 104(4): 455-475.

Hieatt, C. B. (1996): "The Middle English Culinary Recipes in MS Harley 5401: An Edition and Commentary". Medium AEvum LXV(1): 54-71.

Hunt, Tony (1990): Popular Medicine in Thirteenth-Century England: Introduction and Texts. Cambridge: Brewer.

Jones, Claire (1998): "Formula and Formulation. 'Efficacy Phrases' in Medieval English Medical Manuscripts". Neuphilologische Mitteilungen 99(2): 199-209.

Mäkinen, Martti (2006): Between Herbals et alia: Intertextuality in Medieval English Herbals. Ph.D. thesis. Helsinki: University of Helsinki.

Marqués-Aguado, Teresa (2008): Edition and Philological Study of G.U.L. MS Hunter 513 (ff. 37v-96v). Unpublished Ph.D. thesis. Málaga: University of Málaga.

Miranda-García, Antonio, et al. (comps.) (2007-2011): Corpus of Late Middle English Scientific Prose. Málaga: University of Málaga. <http://hunter.uma.es>. (Accessed 20 January 2014).

Nicaise, Edouard (trans.) (1890): La Grande Chirvrgie de Gvy de Chavliac. Chirvrgien, Maistre en Médecine de l'Université de Montpellier. Composée en l'an 1363. Paris: Ancienne Libraire Germer Bailliére et $\mathrm{C}^{\mathrm{ie}}$.

Nicaise, Édouard (trans.) (1893): Chirurgie de Maitre Henri de Mondeville. Chirurgien de Philip le Bel, Roi de France. Composée de 1306 à 1320. Paris: Ancienne Libraire Germer Bailliére et $C^{\text {ie }}$.

Ogden, M. S. (ed.) (1971): The Cyrurgie of Guy de Chauliac. vol. 1 (EETS O.S. 265). London, New York, Toronto: Oxford University Press.

Oxford English Dictionary. <http://www.oed.com>. (Accessed 20 January 2014). 
Pahta, Päivi (1998): Medieval Embryology in the Vernacular: the Case of De Spermate. Helsinki: Société Néophilologique.

Pahta, Päivi and Irma Taavitsainen (2004): "Vernacularisation of scientific and medical writing in its sociohistorical context". In I. Taavitsainen and P. Pahta, eds., Medical and Scientific Writing in Late Medieval England. Cambridge: Cambridge University Press, 1-22.

Quintana-Toledo, Elena (2009): "Middle English Medical Recipes: A Metadiscursive Approach". Studia Anglica Posnaniensia 45(2): 21-38.

Rawcliffe, Carole (1995): Medicine and Society in Later Medieval England. Stroud: Alan Sutton.

Stannard, Jerry (1982): "Rezeptliteratur as Fachliteratur". In W. Eamon, ed., Studies on Medieval Fachliteratur: Proceedings of the Special Session on Medieval Fachliteratur of the Sixteenth International Congress on Medieval Studies. Brussels: Omirel, 59-73.

Taavitsainen, Irma (1994): "On the Evolution of Scientific Writings from 1375 to 1675: Repertoire of Emotive Features". In F. Fernández, M. Fuster, and J. J. Calvo, eds., English Historical Linguistics 1992. Papers from the 7th International Conference on English Historical Linguistics. Amsterdam, Philadelphia: John Benjamins, 329-342.

Taavitsainen, Irma (2001): "Middle English Recipes. Genre characteristics, text type features and underlying traditions of writing." Journal of Historical Pragmatics 2(1): 85-113.

Taavitsainen, Irma (2006 [1994]): "Medical Discourse: Early Genres, $14^{\text {th }}$ and $15^{\text {th }}$ Centuries". In K. Brown, ed., Encyclopedia of Language and Linguistics, vol. 7. Oxford: Elsevier, 688694.

Taavitsainen, Irma and Päivi Pahta (1998): "Vernacularisation of Medical Writing in English: A Corpus-Based Study of Scholasticism”. Early Science and Medicine 3(2): 157-185.

Taavitsainen, Irma, Päivi Pahta and Martti Mäkinen (2006): "Towards a Corpus-Based History of Specialized Languages: Middle English Medical Texts". In R. Facchinetti and M. Rissanen, eds., Corpus-based Studies of Diachronic English. Bern, Berlin, Bruxelles, Frankfurt am Main, New York, Oxford, Wien: Peter Lang, 79-93.

Voigts, Linda E. (1986 [1984]): "Medical Prose". In A. S. G. Edwards, ed., Middle English Prose: a Critical Guide to Major Authors and Genres. New Brunswick: Rutgers University Press, 315-335.

Young, John and P. Henderson Aitken (1908): A Catalogue of the Manuscripts in the Library of the Hunterian Museum in the University of Glasgow. Planned and Begun by the Late John Young, Continued and Completed by P. Henderson Aitken. Glasgow: Maclehose. 